\title{
Syntheses, Structures, and Electrochemical Properties of Platinum(II) \\ Complexes Containing Di-tert-butylbipyridine and Crown Ether \\ Annelated Dithiolate Ligands
}

Yong Ji, Rui Zhang, Yu-Jia Li, Yi-Zhi Li, Jing-Lin Zuo* and Xiao-Zeng You

\section{Supporting Materials}

Index

Page

Table S1. Absorption bands for complex 6 as a function of solvents.

Table S2. Absorption bands for complex 7 as a function of solvents.

Figure S1. The packing diagram of compound IIIc view along the $b$ axis (the dotted line representing S $\cdots$ S non-bonded contacts less than $3.7 \AA$ ).

Figure S2. The packing diagram of the complex $\mathbf{5}$ view along the $b$ axis (the dotted line representing the shorter Pt...N non-bonded contacts).

Figure S3. The packing diagram of the complex 6 view along the $b$ (Top) and $c$ axes (Bottom), respectively (the dotted line representing the shorter Pt...Pt non-bonded contacts).

Figure S4. Charge-transfer-to-diimine absorption band for complex [Pt(dbbpy)(dtdt)] (1) in (a) $\mathrm{CH}_{2} \mathrm{Cl}_{2}$, (b) $\mathrm{CHCl}_{3}$, (c) THF, (d) DMF, (e) DMSO.

Figure S5. Charge-transfer-to-diimine absorption band for complex [Pt(dbbpy)(ptdt)] (2) in (a) $\mathrm{CH}_{2} \mathrm{Cl}_{2}$, (b) $\mathrm{CHCl}_{3}$, (c) THF, (d) DMF, (e) DMSO.

Figure S6. Charge-transfer-to-diimine absorption band for complex [Pt(dbbpy)(mtdt)] (3) in (a) $\mathrm{CH}_{2} \mathrm{Cl}_{2}$, (b) $\mathrm{CHCl}_{3}$, (c) THF, (d) DMF, (e) DMSO.

Figure S7. Charge-transfer-to-diimine absorption band for complex [Pt(dbbpy)(btdt)] (4) in (a) $\mathrm{CH}_{2} \mathrm{Cl}_{2}$, (b) $\mathrm{CHCl}_{3}$, (c) THF, (d) DMF, (e) DMSO.

Figure S8. Plots of frequencies of the LLCT absorption band maxima $\left(v_{\max }\right)$ of complex $[\mathrm{Pt}(\mathrm{dbbpy})(\mathrm{mtdt})]$ (3) versus dielectric constants $(\varepsilon)$ of solvents: (a) $\mathrm{CHCl}_{3}$, (b) THF, (c) $\mathrm{CH}_{2} \mathrm{Cl}_{2}$, (d) DMF, (e) DMSO.

Figure S9. Charge-transfer-to-diimine absorption band for complex [Pt(dbbpy)(3O- $\left.\left.\mathrm{C}_{6} \mathrm{~S}_{8}\right)\right]$ (6) in (a) $\mathrm{CH}_{2} \mathrm{Cl}_{2}$, (b) $\mathrm{CHCl}_{3}$, (c) THF, (d) DMF, (e) DMSO.

Figure S10. Charge-transfer-to-diimine absorption band for complex [Pt(dbbpy)(4O-C $\mathrm{S}_{8}$ )] (7) in (a) $\mathrm{CH}_{2} \mathrm{Cl}_{2}$, (b) $\mathrm{CHCl}_{3}$, (c) THF, (d) DMF, (e) DMSO.

Figure S11. Cyclic voltammograms of IIIc recorded in a mixture of $\mathrm{CH}_{2} \mathrm{Cl}_{2} / \mathrm{CH}_{3} \mathrm{CN}$ $\left(10^{-3} \mathrm{~mol} \mathrm{~L}^{-1}\right)$ at a scan rate of $100 \mathrm{mV} \mathrm{s}^{-1}$ with $n-\mathrm{Bu}_{4} \mathrm{NClO}_{4}(0.1 \mathrm{M})$ as the supporting electrolyte in the presence of increasing amounts of $\mathrm{Na}^{+}$.

\footnotetext{
* To whom correspondence should be addressed. Email: zuojl@nju.edu.cn. Fax: +86-25-83314502.
} Nanjing University. 
Table S1. Absorption bands for complex 6 as a function of solvents.

\begin{tabular}{ccc}
\hline & UV-vis $\lambda_{\text {max }}, \mathrm{nm}$ & $\varepsilon, 10^{4} \mathrm{M}^{-1} \mathrm{~cm}^{-1}$ \\
\hline \multirow{2}{*}{ solvent } & 586 & 0.5597 \\
& 292 & 4.9228 \\
& 585 & 0.2848 \\
$\mathrm{DMF}$ & 292 & 2.4376 \\
& 637 & 0.3063 \\
$\mathrm{CH}_{2} \mathrm{Cl}$ & 296 & 2.6510 \\
& 647 & 0.3316 \\
$\mathrm{THF}$ & 298 & 2.8561 \\
$\mathrm{CHCl}_{3}$ & 677 & 0.4183 \\
& 299 & 3.4694 \\
\hline
\end{tabular}

Table S2. Absorption bands for complex 7 as a function of solvents.

\begin{tabular}{ccc}
\hline solvent & UV-vis $\lambda_{\text {max }}, \mathrm{nm}$ & $\varepsilon, 10^{4} \mathrm{M}^{-1} \mathrm{~cm}^{-1}$ \\
& 583 & 0.7913 \\
DMSO & 291 & 6.7962 \\
& 585 & 0.5314 \\
$\mathrm{DMF}$ & 293 & 4.4888 \\
& 632 & 0.6253 \\
$\mathrm{CH}_{2} \mathrm{Cl}_{2}$ & 297 & 5.6627 \\
& 232 & 5.3342 \\
& 652 & 0.9114 \\
$\mathrm{THF}$ & 300 & 7.0394 \\
$\mathrm{CHCl}_{3}$ & 665 & 0.7430 \\
& 300 & 6.8688 \\
& 247 & 5.4806 \\
\hline
\end{tabular}




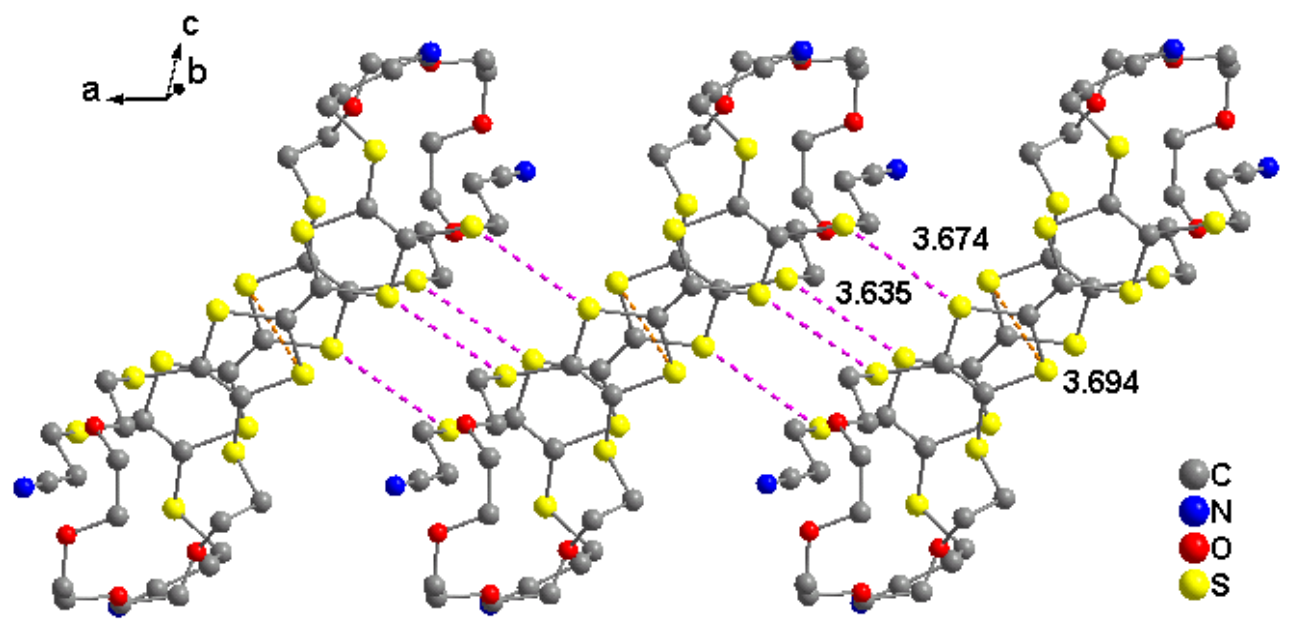

Figure S1. The packing diagram of compound IIIc viewing along the $b$ axis (the dotted line representing S $\cdots$ S non-bonded contacts less than $3.7 \AA$ ).

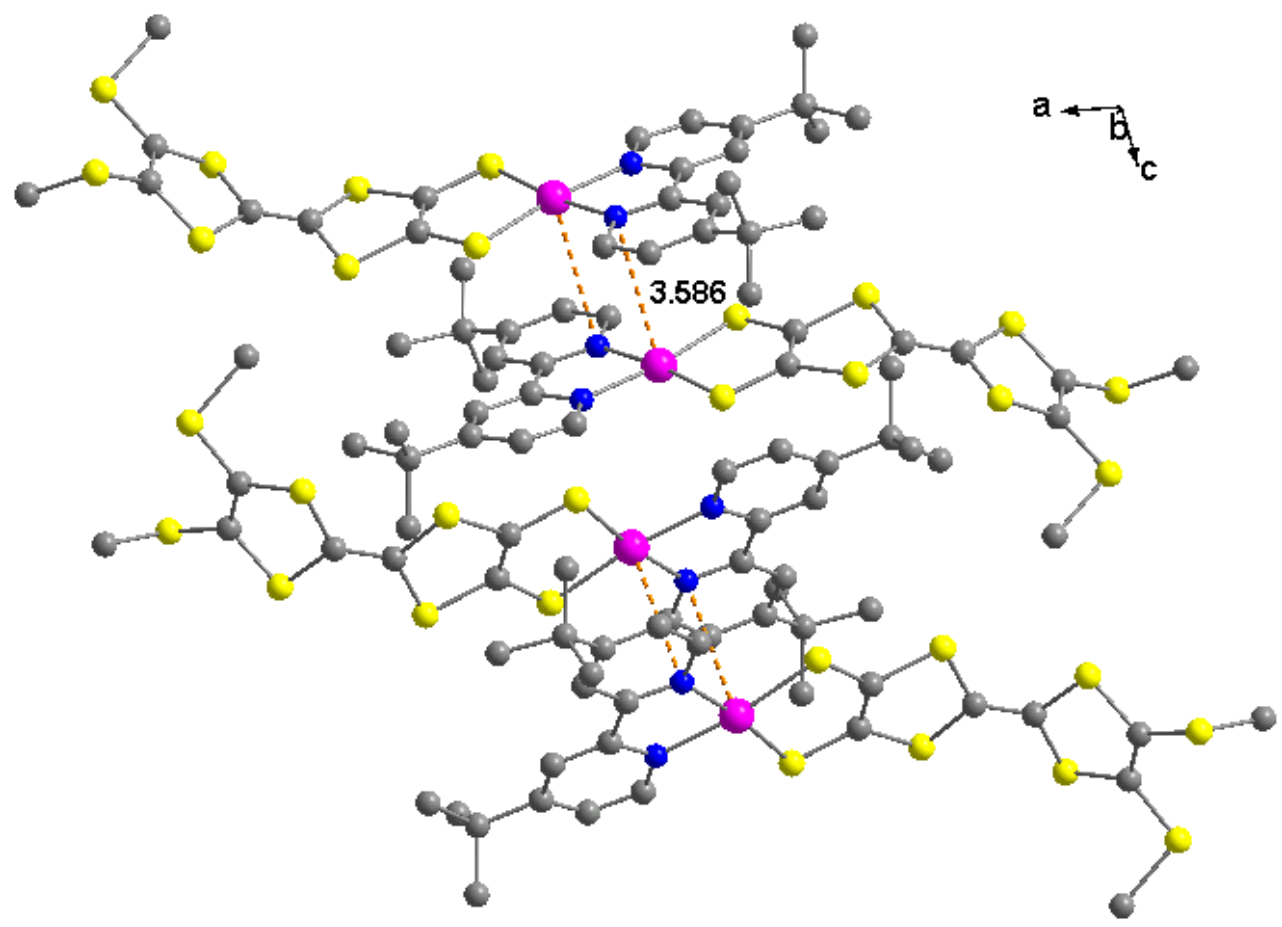

Figure S2. The packing diagram of the complex $\mathbf{5}$ viewing along the $b$ axis (the dotted

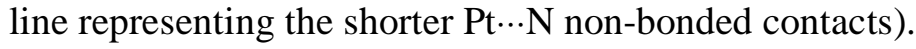




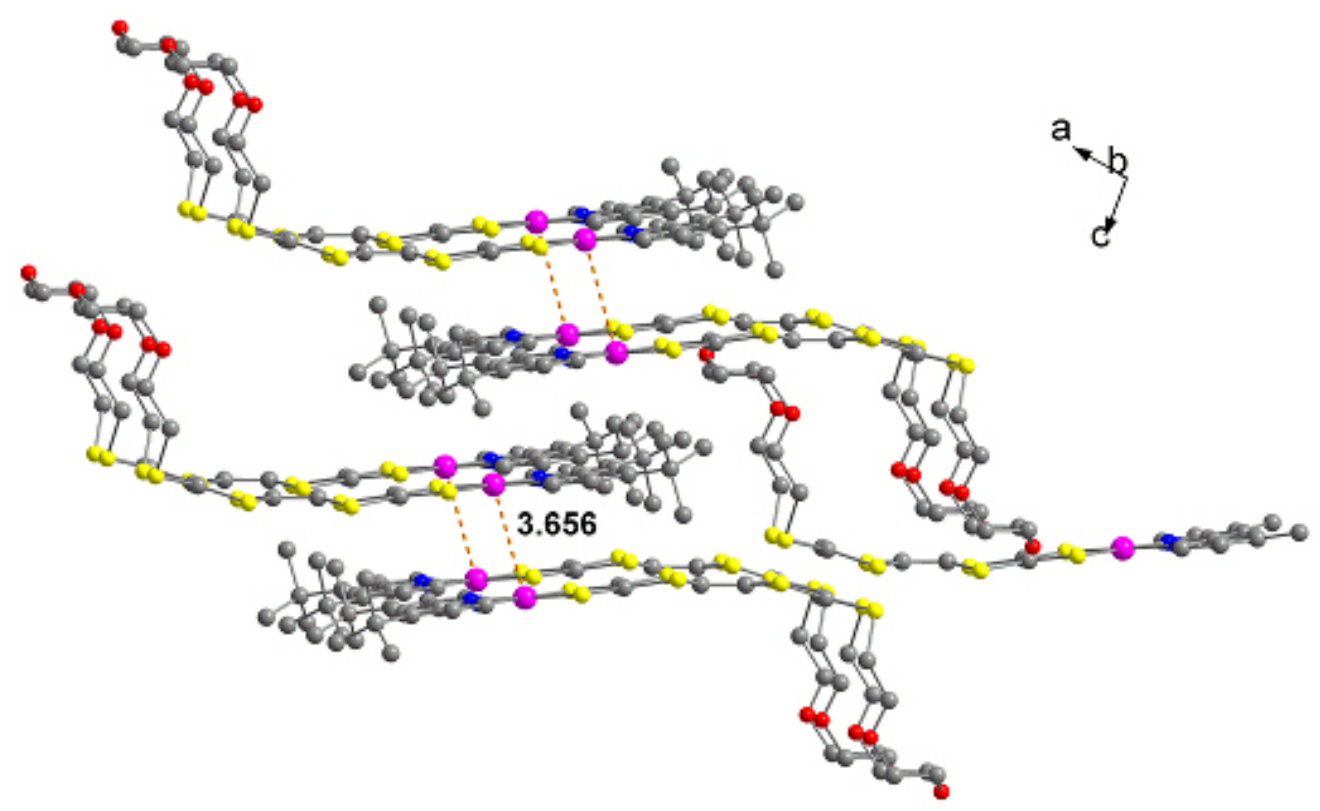

(a)

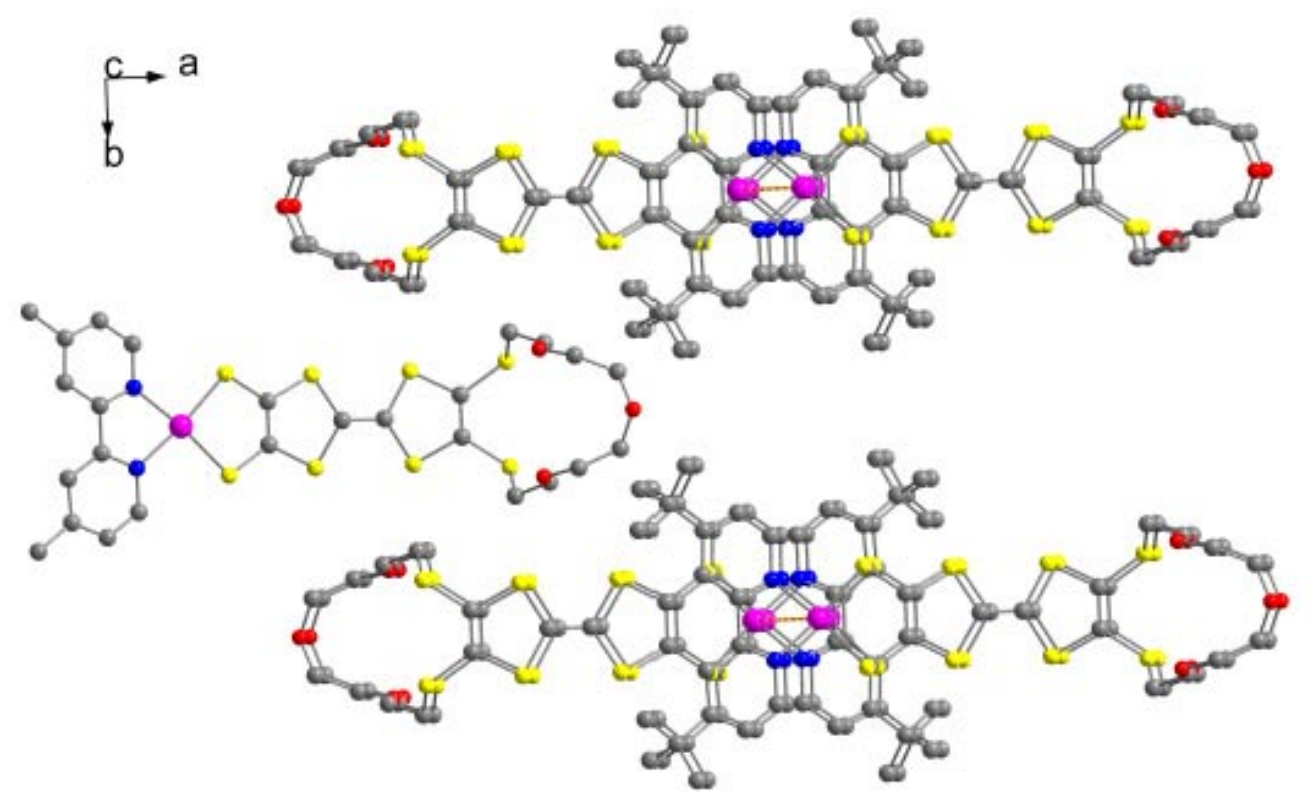

(b)

Figure S3. The packing diagram of the complex 6 viewing along the $b$ (Top) and $c$ axes (Bottom), respectively (the dotted line representing the shorter Pt...Pt non-bonded contacts). 


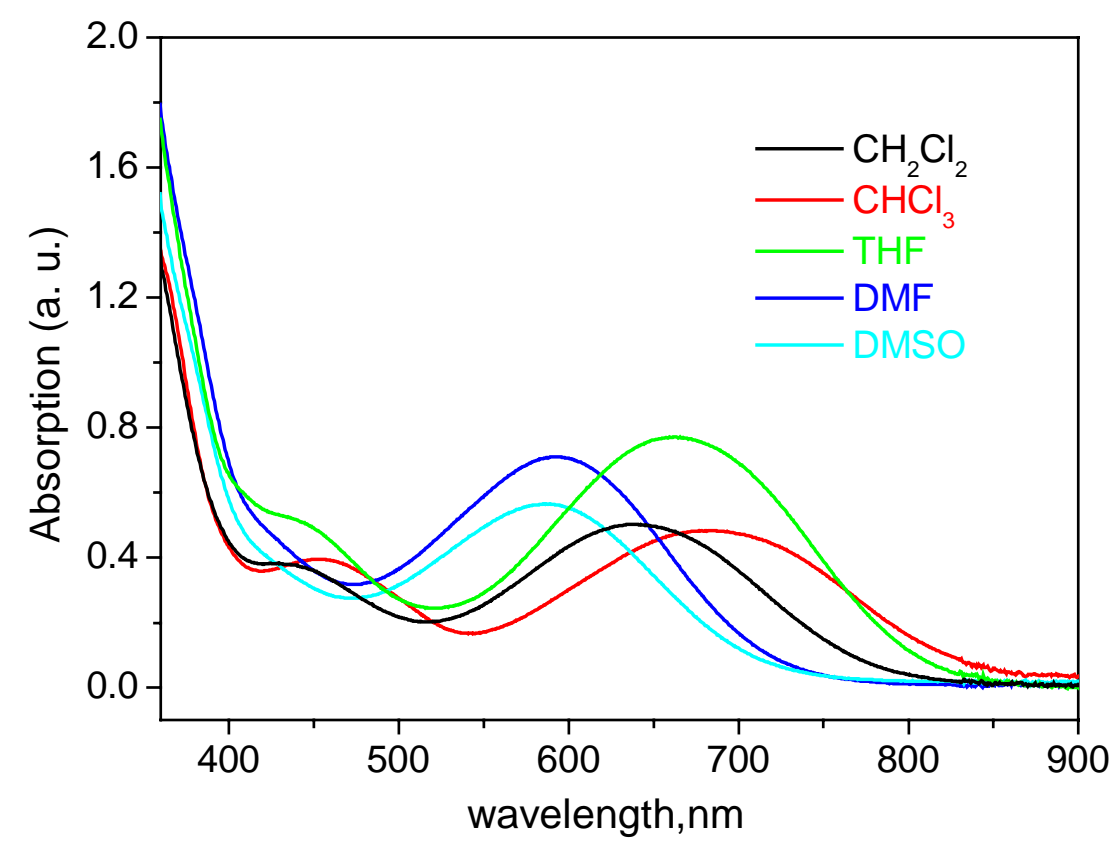

Figure S4. Charge-transfer-to-diimine absorption band for complex [Pt(dbbpy)(dtdt)] (1) in (a) $\mathrm{CH}_{2} \mathrm{Cl}_{2}$, (b) $\mathrm{CHCl}_{3}$, (c) THF, (d) DMF, (e) DMSO.

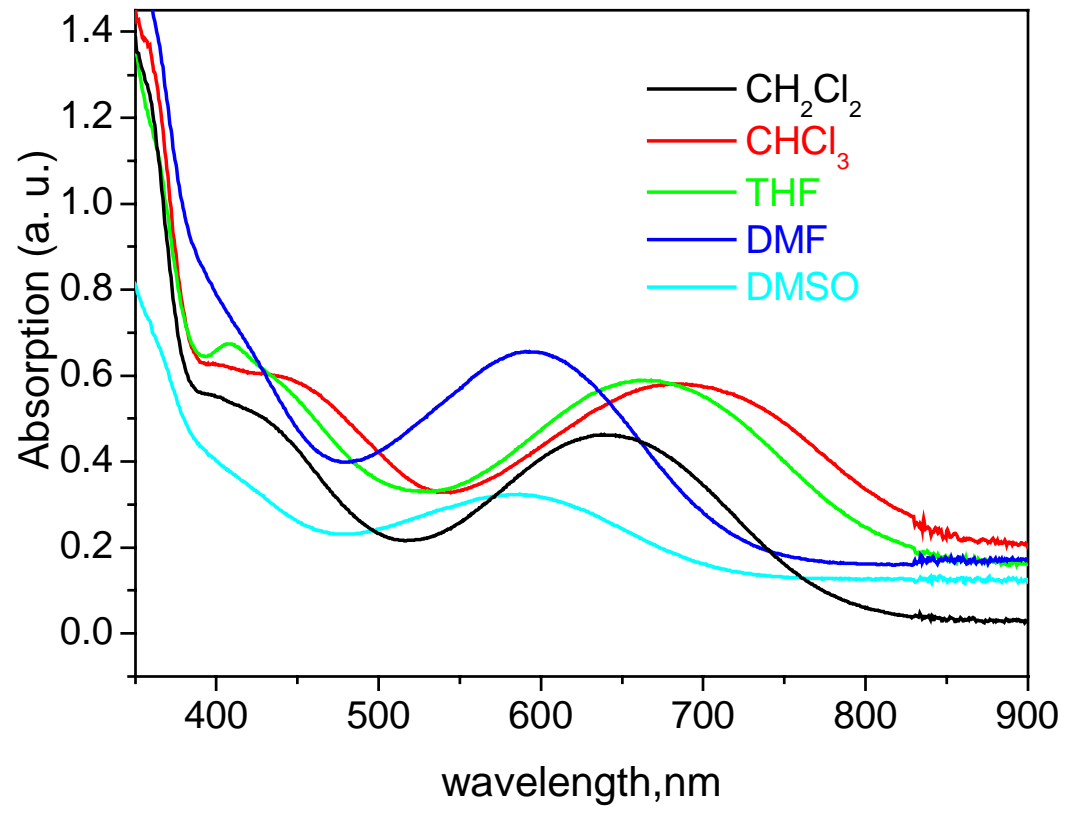

Figure S5. Charge-transfer-to-diimine absorption band for complex [Pt(dbbpy)(ptdt)] (2) in (a) $\mathrm{CH}_{2} \mathrm{Cl}_{2}$, (b) $\mathrm{CHCl}_{3}$, (c) THF, (d) DMF, (e) DMSO. 


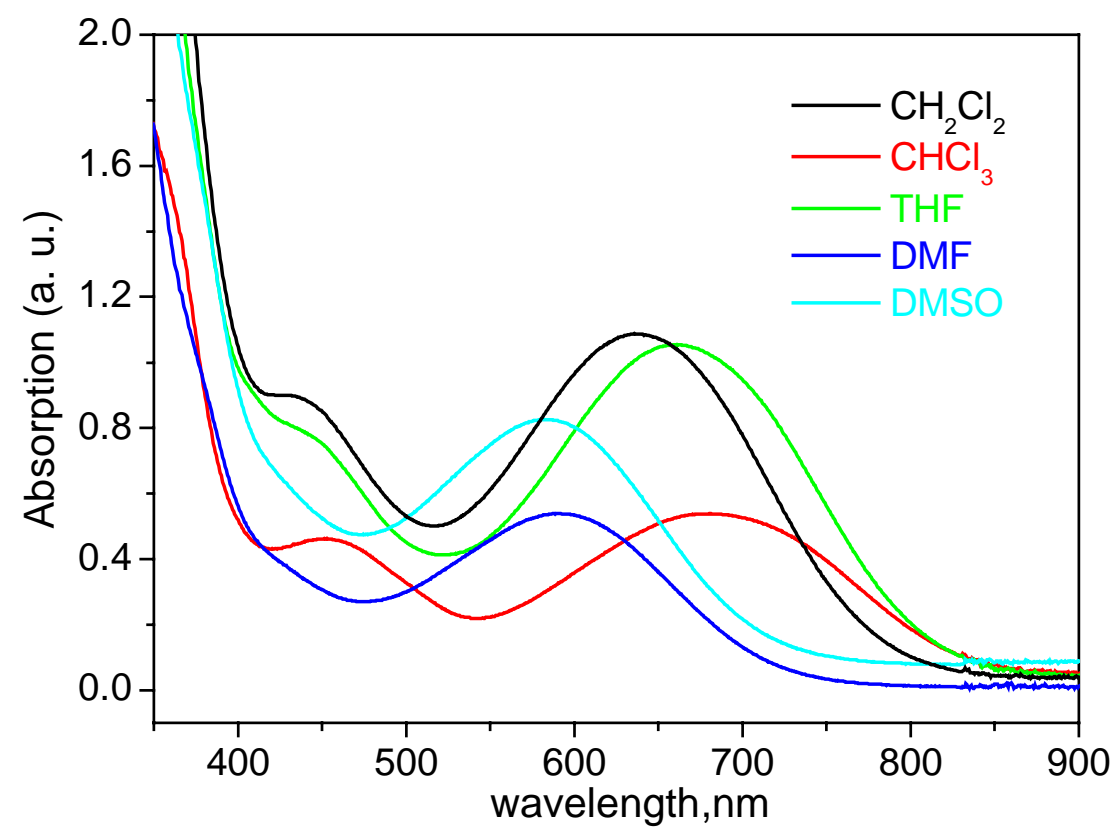

Figure S6. Charge-transfer-to-diimine absorption band for complex [Pt(dbbpy)(mtdt)] (3) in (a) $\mathrm{CH}_{2} \mathrm{Cl}_{2}$, (b) $\mathrm{CHCl}_{3}$, (c) THF, (d) DMF, (e) DMSO.

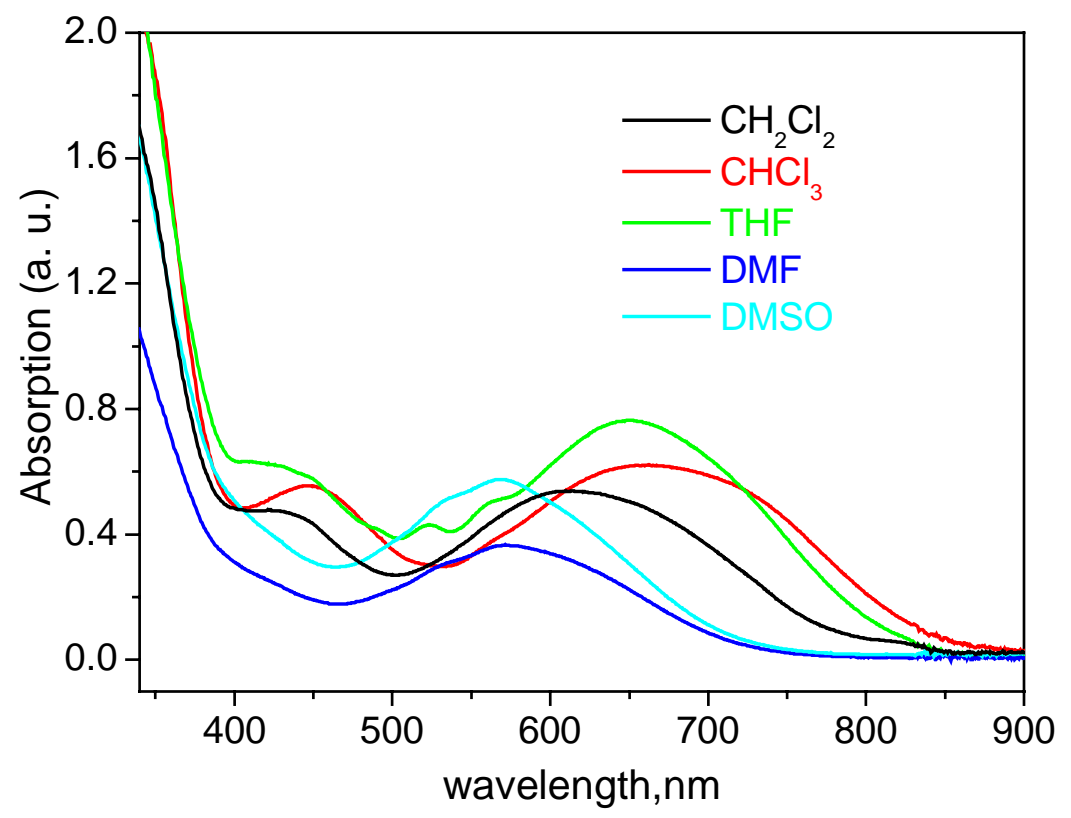

Figure S7. Charge-transfer-to-diimine absorption band for complex [Pt(dbbpy)(btdt)] (4) in (a) $\mathrm{CH}_{2} \mathrm{Cl}_{2}$, (b) $\mathrm{CHCl}_{3}$, (c) THF, (d) DMF, (e) DMSO. 


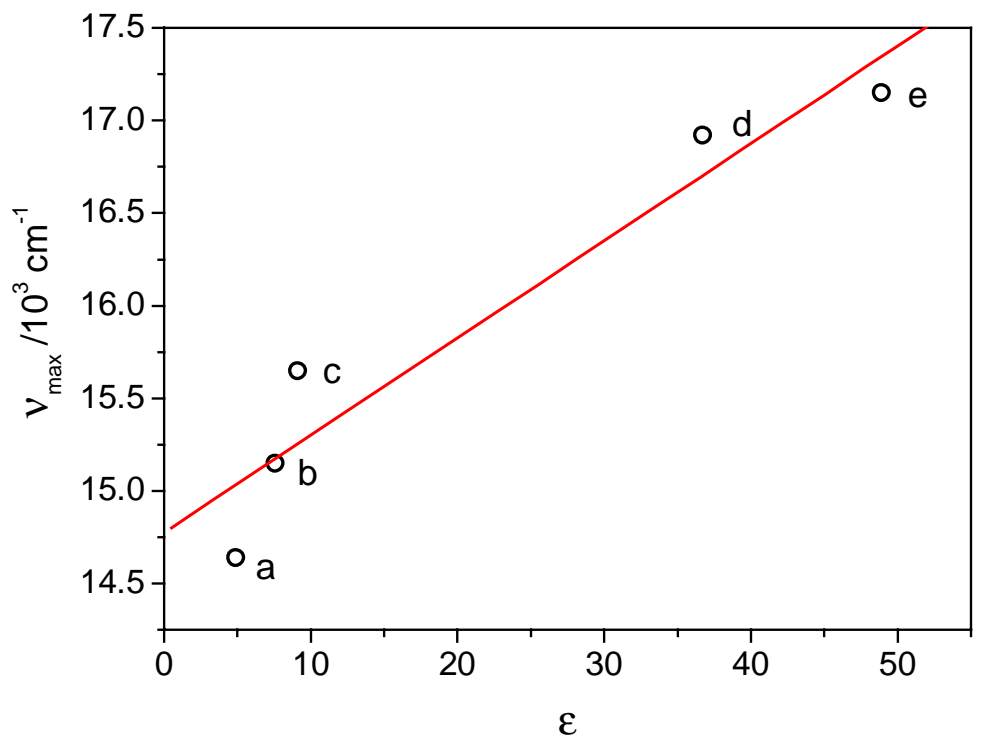

Figure S8. Plots of frequencies of the LLCT absorption band maxima $\left(v_{\max }\right)$ of complex $[\mathrm{Pt}(\mathrm{dbbpy})(\mathrm{mtdt})](3)$ versus dielectric constants $(\varepsilon)$ of solvents: (a) $\mathrm{CHCl}_{3}$, (b) THF, (c) $\mathrm{CH}_{2} \mathrm{Cl}_{2}$, (d) DMF, (e) DMSO.

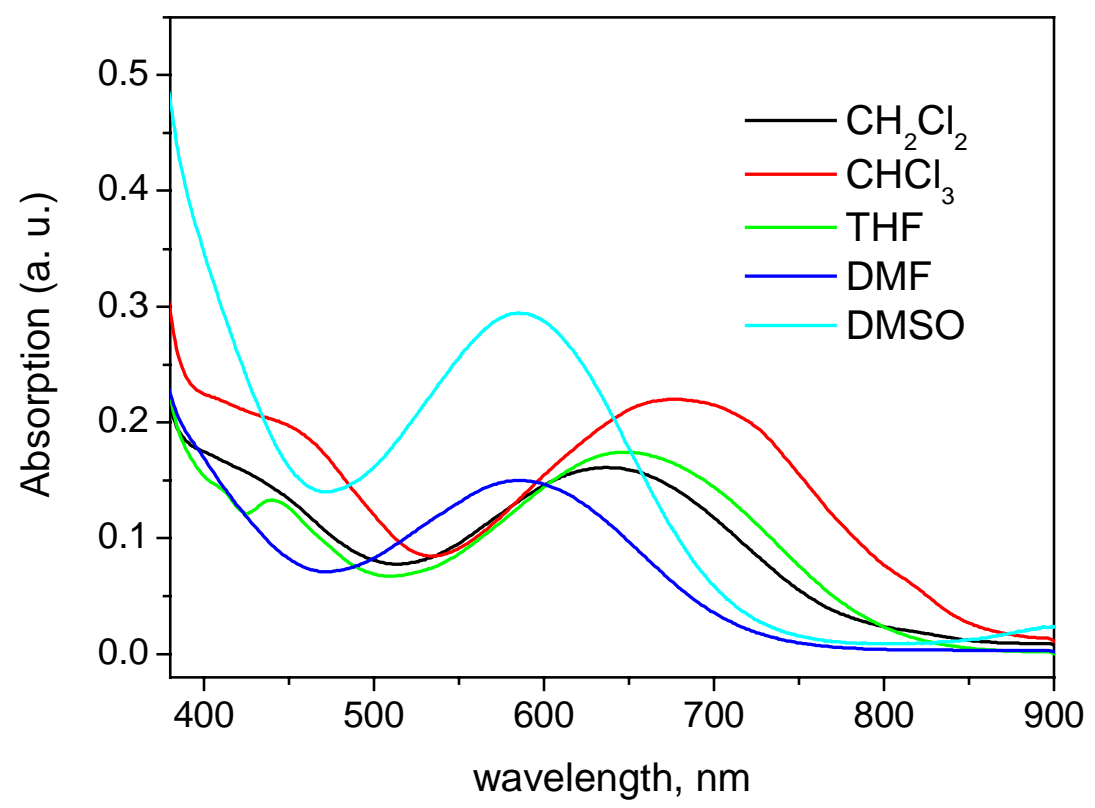

Figure S9. Charge-transfer-to-diimine absorption band for complex [Pt(dbbpy)(3O- $\left.\left.\mathrm{C}_{6} \mathrm{~S}_{8}\right)\right]$ (6) in (a) $\mathrm{CH}_{2} \mathrm{Cl}_{2}$, (b) $\mathrm{CHCl}_{3}$, (c) THF, (d) DMF, (e) DMSO. 


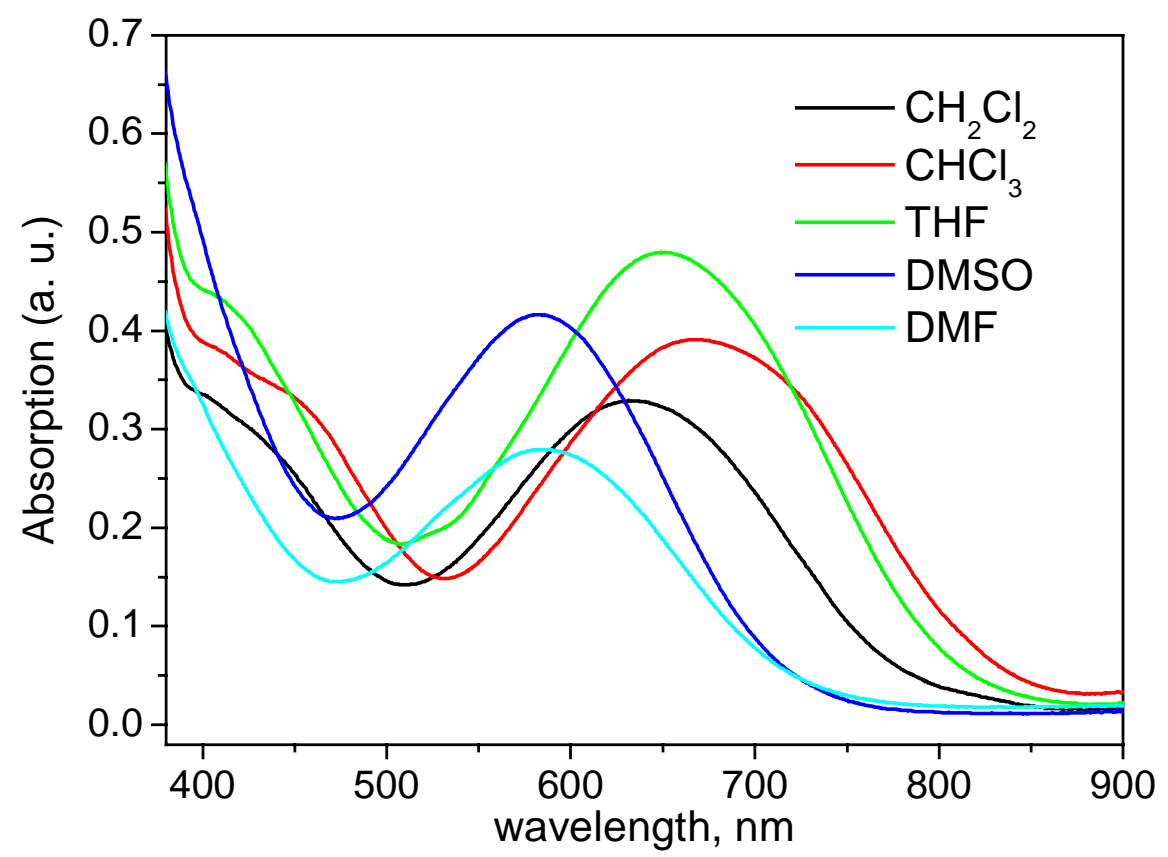

Figure S10. Charge-transfer-to-diimine absorption band for complex [Pt(dbbpy)(4O-C $\left.\left.\mathrm{C}_{8}\right)\right]$ (7) in (a) $\mathrm{CH}_{2} \mathrm{Cl}_{2}$, (b) $\mathrm{CHCl}_{3}$, (c) THF, (d) DMF, (e) DMSO.

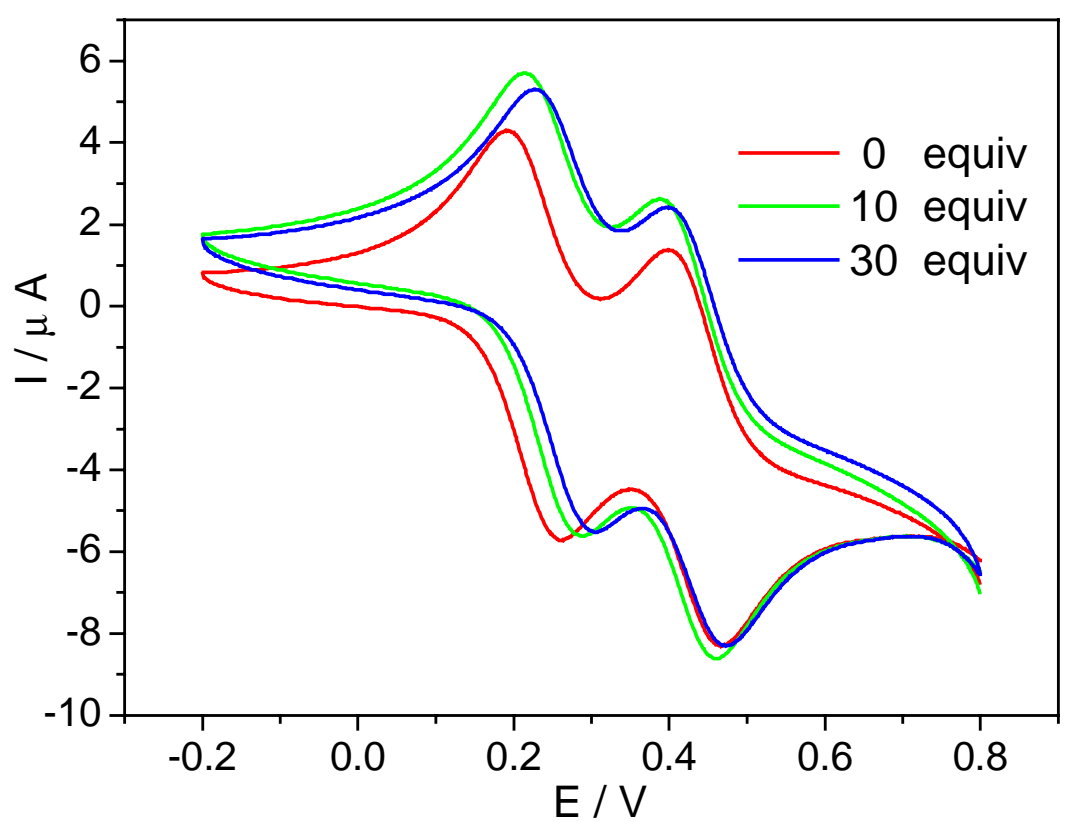

Figure S11. Cyclic voltammograms of IIIc recorded in a mixture of $\mathrm{CH}_{2} \mathrm{Cl}_{2} / \mathrm{CH}_{3} \mathrm{CN}$ $\left(10^{-3} \mathrm{~mol} \mathrm{~L}^{-1}\right)$ at a scan rate of $100 \mathrm{mV} \mathrm{s}^{-1}$ with $n-\mathrm{Bu}_{4} \mathrm{NClO}_{4}(0.1 \mathrm{M})$ as the supporting electrolyte in the presence of increasing amounts of $\mathrm{Na}^{+}$. 